\title{
Conf-950875--1
}

UCRL-JC-120645

PREPRINT

\section{OH Generation in Steam-Air Pulsed Corona}

\author{
Manuel Garcia \\ Britton Chang
}

This paper was prepared for submittal to the 12th International Symposium on Plasma Chemistry Minneapolis, $M N$

August 21-25, 1995

May 1995

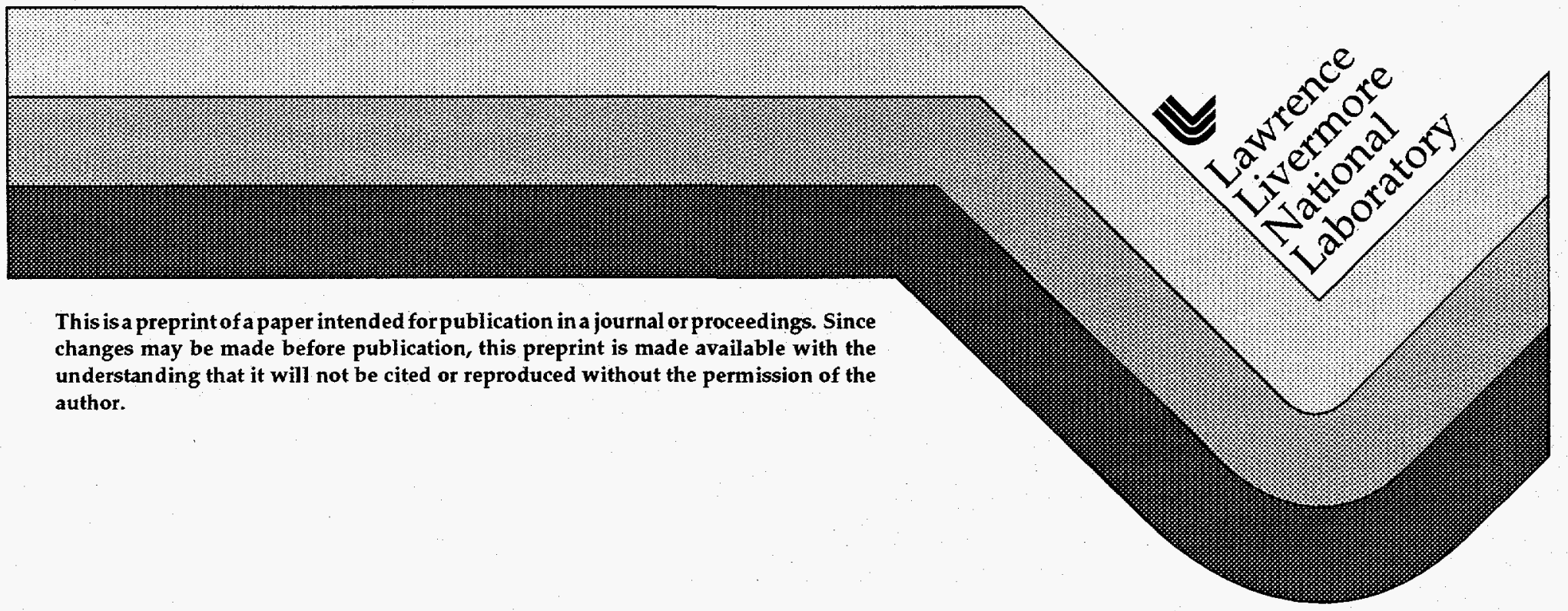




\section{DISCLAIMER}

This document was prepared as an account of work sponsored by an agency of the United States Government. Neither the United States Government nor the University of California nor any of their employees, makes any warranty, express or implied, or assumes any legal liability or responsibility for the accuracy, completeness, or usefulness of any information, apparatus, product, or process disclosed, or represents that its use would not infringe privately owned rights. Reference herein to any specific commercial product, process, or service by trade name, trademark, manufacturer, or otherwise, does not necessarily constitute or imply its endorsement, recommendation, or favoring by the United States Government or the University of California. The views and opinions of authors expressed herein do not necessarily state or reflect those of the United States Government or the University of California, and shall not be used for advertising or product endorsement purposes.

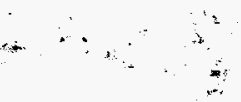




\section{DISCLAIMER}

Portions of this document may be illegible in electronic image products. Images are produced from the best available original document. 


\title{
OH GENERATION IN STEAM-AIR PULSED CORONA
}

\author{
Manuel Garcia, Britton Chang \\ Lawrence Livermore National Laboratory \\ Livermore, CA 94550
}

The measurement of $\mathrm{OH}$ concentration in a pulsed corona discharge through a steam-air mixture is compared with a chemical kinetics model. The original motivation was to develop a technological hydroxilizer for oxidizing gas pollutants to acids. Time dependent measurements of the $3064 \AA$ emission of $\mathrm{OH}$ indicate a production of nearly $4 \mathrm{ppm}\left(\approx 10^{14} \mathrm{~cm}^{-3}\right)$ within a spark. This measurement was accomplished by a $1 \mathrm{~ns}$ resolution photomultiplier with a $100 \AA$ filter centered at $3080 \AA$. The discharge occurs across a $1 \mathrm{~cm}$ coaxial gap between a central anode tube and an outer cylindrical cathode cased in glass and at ground potential. The water-air mixture is of equal proportions and at 1 atmosphere. Pulsed voltage of $38 \mathrm{kV}$ and $60 \mathrm{~ns}$ risetime produces a $60 \mathrm{~A}, 20 \mathrm{~ns}$ spark. The model predicts comparable $\mathrm{OH}$ production by dissociation in the air-water mixture after $100 \mathrm{~ns}$ of $10^{12}$ electrons $/ \mathrm{cm}^{3}$. The electron density is set to zero during the subsequent $100 \mu \mathrm{s}$ in the model, and thereafter $\mathrm{OH}$ is seen as a short-lived reaction product of $\mathrm{HO}_{2}$ with $\mathrm{O}$ and $\mathrm{N}$ atoms. The sequence of reaction is: $100 \mathrm{~ns}$ of dissociation to peak $\mathrm{OH}$ concentration, $0.2 \mu \mathrm{s}$ for hydrogen atom loss and $\mathrm{HO}_{2}$ formation, $20 \mu$ s for $\mathrm{O}$ atom loss and $\mathrm{O}_{3}$ formation, beyond $20 \mu \mathrm{s}$ NO formation from $\mathrm{N}$ atoms with $\mathrm{OH}$ and $\mathrm{HO}_{2}$. In the model $\mathrm{HO}_{2}$ ultimately decays by slowly forming $\mathrm{H}_{2} \mathrm{O}_{2}$, so it may be viewed as a stable fuel which produces $\mathrm{OH}$ when combined with atomic oxygen or nitrogen.

\section{MASTER}




\section{Introduction and Experiment}

This work compares the measurement of $\mathrm{OH}$ concentration in a pulsed corona discharge through a steam-air mixture, and a chemical kinetics model. The original motivation was to utilize $\mathrm{OH}$ for gas processing applications, [1].
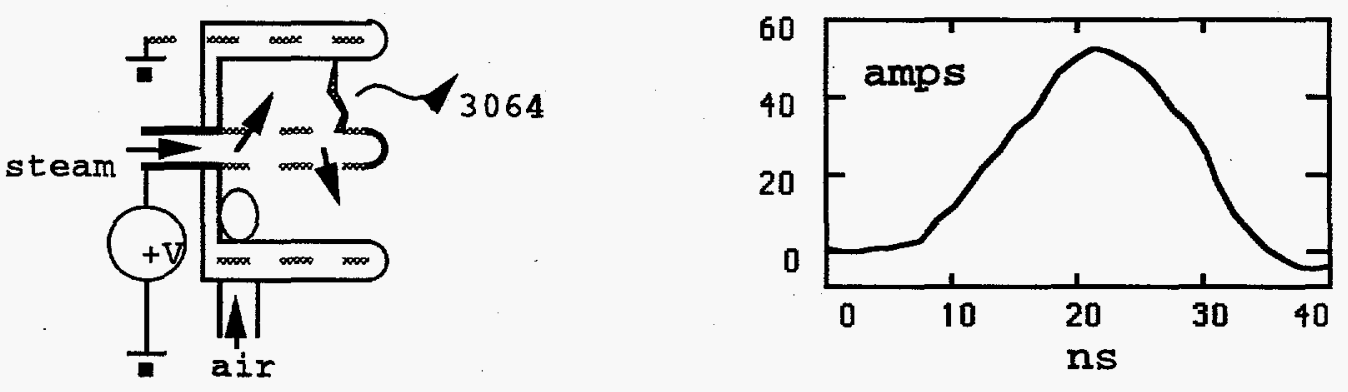

Figure 1: Schematic of coaxial-barrier steam-air discharge, and a sample current pulse

The discharge occurs across a $1 \mathrm{~cm}$ coaxial gap between a central anode tube $(0.64 \mathrm{~cm}$ in diameter, $5 \mathrm{~cm}$ long), and an outer cylindrical cathode mesh $(2.5 \mathrm{~cm}$ diameter) cased in glass and at ground potential. Steam is introduced through twenty-four $0.2 \mathrm{~mm}$ holes along the anode. Air is introduced at the base of the discharge as a swirl flow of 20 liters/minute. The water-air mixture is of equal proportions and at 1 atmosphere. Pulsed voltage of $38 \mathrm{kV}$ and $60 \mathrm{~ns}$ risetime produces a $60 \mathrm{~A}, 20 \mathrm{~ns}$ spark.

Figure 2 shows a measurement of the $3064 \AA$ emission of $\mathrm{OH}$ during the current pulse.

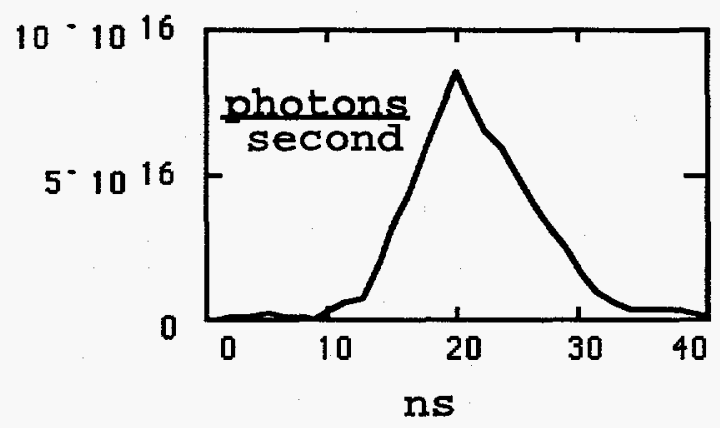

Figure 2: Measurement of $\mathrm{OH} 3064$ Å emission.

This pulse represents a total of $10^{9}$ photons. As corona streamer diameters are between 20 to 100 microns, [2], the streamer volume in this experiment is below $10^{-4} \mathrm{~cm}^{3}$ which indicates an $\mathrm{OH}$ concentration of up to $10^{14} \mathrm{~cm}^{-3}$. By taking 1 ppm as equal to one millionth the density of dry air, or $2.69 \times 10^{13} \mathrm{~cm}^{-3}$ for 
comparative purposes, the $\mathrm{OH}$ concentration in the experiment is between 3 and $4 \mathrm{ppm}$. The measurement was accomplished by a photomultiplier with a temporal resolution of $1 \mathrm{~ns}$, and a $100 \AA$ bandpass filter centered at $3080 \AA$.

\section{Chemical Kinetics Model}

The chemical kinetics model includes thirty four reactions involving the twelve species: $\mathrm{H}_{2}, \mathrm{O}_{2}, \mathrm{NO}, \mathrm{N}_{2}, \mathrm{H}_{2} \mathrm{O}, \mathrm{H}, \mathrm{O}, \mathrm{N}, \mathrm{OH}, \mathrm{HO}_{2}, \mathrm{H}_{2} \mathrm{O}_{2}$, and $\mathrm{O}_{3}$. Rate coefficients for dissociation are calculated from a Boltzmann model [3], all other reaction rates are taken from Mätzing [4] at a temperature of $300_{i} \mathrm{~K}$. In this model all species are assumed to be in the gas phase, no attempt is made to model the actual mixture of air, water vapor, fog, and mist. Electrons dissociate hydrogen, oxygen, nitrogen, water, and NO. Ozone only appears as a sink, there are no oxidation reactions by ozone. The initial mixture is comprised of equal concentrations of water and air each at $2.69 \times 10^{19} \mathrm{~cm}^{-3}$, where the model air is composed of $79 \%$ nitrogen and $21 \%$ oxygen. During the initial interval of 100 ns electron density is held constant at $10^{12} \mathrm{~cm}^{-3}$, and the dissociation rate coefficients are specified for a Townsend parameter of $125 \mathrm{Td}$. The electron density is then set to zero and the system allowed to evolve for $100 \mu \mathrm{s}$. Solution is effected by simultaneous forward integration of twelve rate equations, 2000 time steps are used in each of the two time domains ( $\Delta t=0.05 \mathrm{~ns}$ for $100 \mathrm{~ns}$, then $\Delta \mathrm{t}=50 \mathrm{~ns}$ for $100 \mu \mathrm{s})$. Results are shown in ppm as defined earlier.

The chemical kinetics model predicts the same $\mathrm{OH}$ production from the air-water mixture after $100 \mathrm{~ns}$ of $10^{12}$ electrons $/ \mathrm{cm}^{3}$. In the subsequent $100 \mu \mathrm{s}$ of electron-free evolution, $\mathrm{OH}$ is seen as a short-lived product of reactions between $\mathrm{HO}_{2}$ with oxygen and nitrogen atoms, until these atoms have recombined into molecules, and the $\mathrm{HO}_{2}$ has been converted to $\mathrm{H}_{2} \mathrm{O}_{2}$. Note reference [5].

During the initial $100 \mathrm{~ns}$ discharge interval $32 \mathrm{ppm}$ of $\mathrm{O}$ atoms are generated, or eight times more than the production of $\mathrm{OH}$. Figure 4 summarizes the other significant species. 


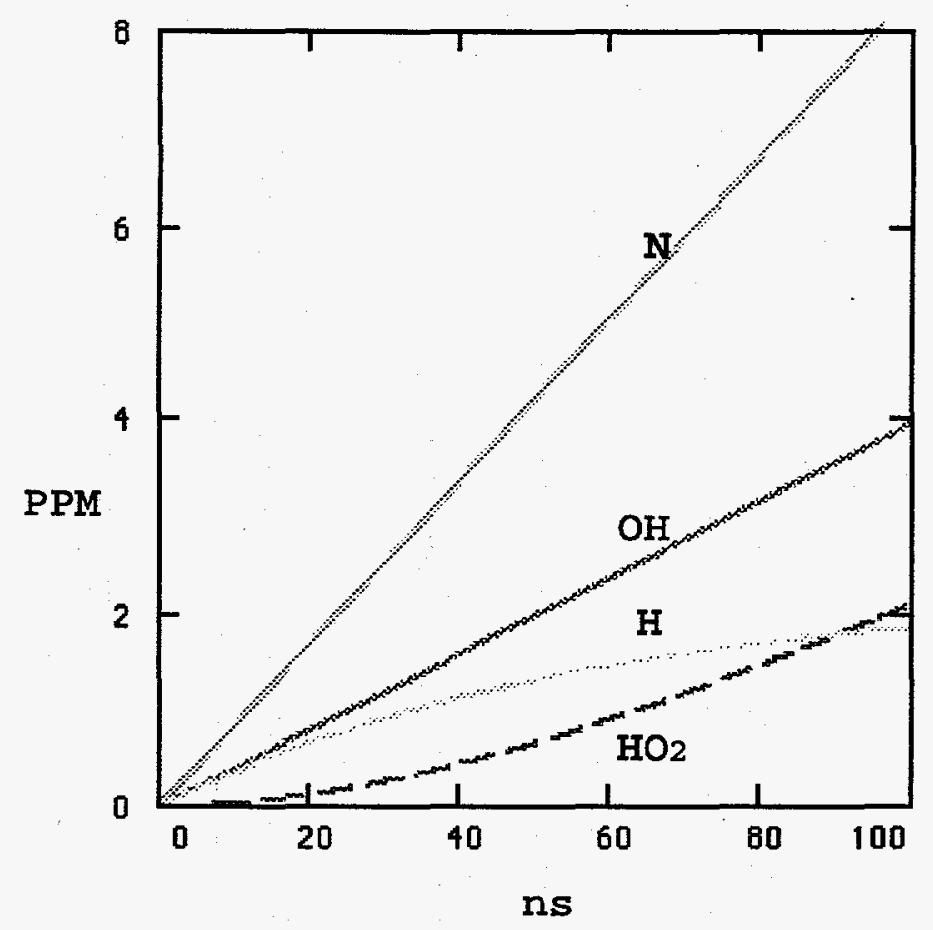

Figure 4: Model discharge interval (also $32 \mathrm{ppm} \mathrm{O)}$

The subsequent $100 \mu$ s of electron-free evolution has three distinct phases extending to: $0.2 \mu \mathrm{s}, 20 \mu \mathrm{s}$, and beyond $20 \mu \mathrm{s}$. During the first $0.2 \mu \mathrm{s}$ hydrogen atoms disappear by combining with $\mathrm{O}_{2}$ to form $\mathrm{HO}_{2}$, see Figure 5 (note log scale).

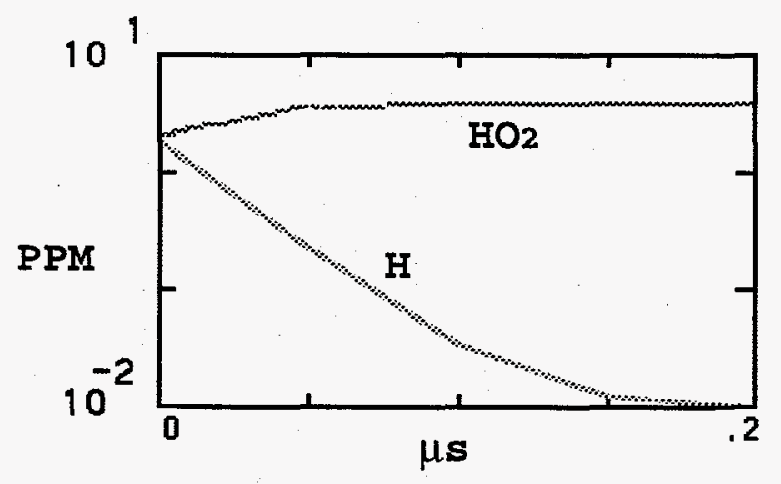

Figure 5: Hydrogen atom loss

During the subsequent evolution a cycle is observed in which $\mathrm{OH}$ reacts with atoms to form $\mathrm{H}$ and molecules, the hydrogen atoms are quickly converted to $\mathrm{HO}_{2}$, and $\mathrm{HO}_{2}$ reacts with atoms to produce $\mathrm{OH}$ and molecules. 
Oxygen atoms dominate this cycle for $20 \mu$ s until ozone formation has scavenged them, then only the slowly recombining nitrogen atoms are involved. Oxygen atoms favor a higher concentration of $\mathrm{OH}$ versus $\mathrm{HO}_{2}$ by their aggressive oxidation of $\mathrm{HO}_{2}$, while nitrogen atoms favor $\mathrm{HO}_{2}$ over $\mathrm{OH}$.

By $100 \mu$ s over 2 ppm of NO has formed, which is nearly $10 \%$ of the ozone concentration. A similar effect was observed during experiments. Figures 6 and 7 summarize these results.

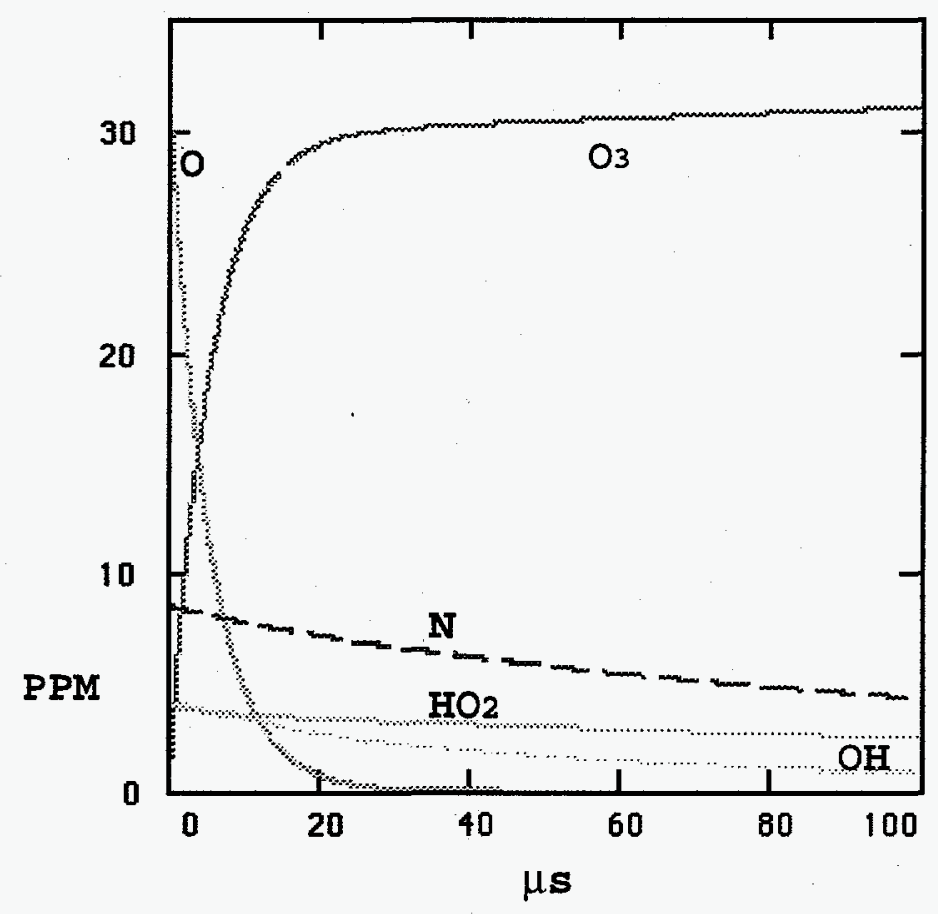

Figure 6: Post-discharge evolution

In the model $\mathrm{HO}_{2}$ decays by the slow process of $\mathrm{H}_{2} \mathrm{O}_{2}$ formation, so it may be viewed as a stable fuel which produces the transitory species $\mathrm{OH}$ when combined with atomic oxygen or nitrogen.

This work was performed under the auspices of the U.S. Dept. of Energy at LLNL under contract no. W-7405-Eng-48. 


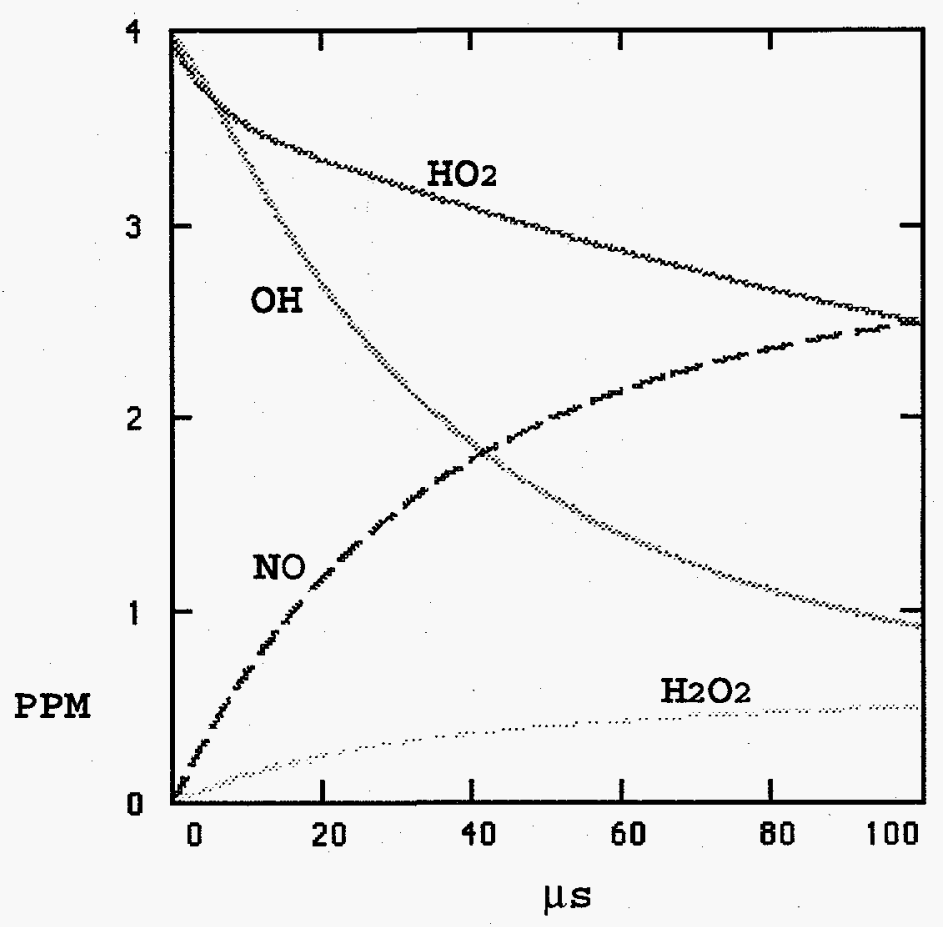

Figure 7: Post-discharge evolution of $\mathrm{OH}$.

\section{References}

[1] B. Chang, M. Garcia, this symposium.

[2] J. Chang, P. Lawless, T. Yamamoto, "Corona Discharge Processes," IEEE Trans. Plasma Sci., vol. 19, pp. 1152-1166, Dec. 1991.

[3] M. Garcia, B. Chang, "Analytical Boltzmann Moments for Electrons in $\mathrm{N}_{2}-\mathrm{O}_{2}-\mathrm{H}_{2} \mathrm{O}$ Gas Mixtures," IEEE Int. Conf. on Plasma Sci. (Santa Fe, NM), June 1994.

[4] H. Mätzing, "Chemical Kinetics of Flue Gas Cleaning by Irradiation with Electrons," Advances in Chemical Physics Volume LXXX, I.Prigogine, S. Rice, Eds., John Wiley \& Sons, New York, 1991, pp. 315-402.

[5] F. Kaufman, F. Del Greco, "Fast Reactions of OH Radicals," Ninth (International) Symposium on Combustion, at Cornell University 1962, Academic Press, New York, 1963, pp. 659668. 